\title{
Acromial Index in Indian Population and its Significance on Rotator Cuff Tears
}

\author{
Sharat Balemane ${ }^{1}$, Kaushik Eswaran ${ }^{1}$, Nishanth Shetty ${ }^{1}$
}

\section{Abstract}

Background: The etiopathogenesis of rotator cuff tears remains debatable. Among the many causes, abnormal scapular morphology has been found to accelerate the degenerative process of rotator cuff tears. The morphology and lateral extension of the acromion process were assessed in detail by Nyffeler et al. and the Acromion Index (AI) was introduced, which measures the lateral extension of the acromion. It was theorized that a large lateral extension of the acromion increased the chances of the supraspinatus tendon to degenerate because of impingement between the acromion and the deltoid muscle. The AI was compared between patients with rotator cuff tears and patients with an intact rotator cuff.

Methods: 21 Indian patients presenting to the orthopaedics OPD, Yenepoya Medical College, with rotator cuff tears were taken up for this study between August 2020 and February 2021. Another 21 patients with intact rotator cuff and other shoulder diseases such as frozen shoulder were included in this study. Patients with rotator cuff tears were included in group A, and patients with intact rotator cuff were included in group B. Both groups had the AI measured on radiographs, and their values were compared.

Results: The mean Acromial Index (AI) in the rotator cuff tear group was 0.74 and in the intact rotator cuff group it was 0.59 , which was statistically significant. There was no statistical difference in AI between male and female patients. The mean age of the patients in the rotator cuff group was 50.8 years, and in non rotator cuff tear group, it was 50.2 years.

Conclusion: Acromial Index is a useful predictive tool for detecting rotator cuff tears in the Indian population. Further studies are required to assess its usefulness in predicting the progression of a rotator cuff tear.

Keywords: Rotator cuff tear; Acromial Index; Shoulder.

\section{Introduction}

The etiopathogenesis of rotator cuff tears is still not completely understood. Several studies have come up with factors that are responsible for development of rotator cuff tears. Neer CS et al. [1] first described the impingement syndrome and the impingement of the acromion bone spur and coracoacromial ligament on the rotator cuff tendon which resulted in a tear. Another theory by Codman EA et al. [2] attributes degenerative changes in the tendon to rotator cuff tears. The anatomy [3] and various parameters of the acromion $[4,5]$, and its relationship with rotator cuff disease have been described by different authors. The morphology of the acromion process was classified into three types [3] based on its appearance in the lateral radiograph. A higher prevalence of rotator cuff tears was seen with hooked type acromion.

The morphology and lateral extension of the acromion process was assessed in detail by Nyffeler et al. and the Acromion Index (AI) was introduced, which measures the lateral extension of the acromion. It was theorized that a large lateral extension of the acromion increased the chances of the supraspinatus tendon to degenerate because of impingement between the acromion and the deltoid muscle [6]. A study by Miyazaki et al. [7] suggested the possibility of racial differences in AI. Acromial Index could also predict the progression of a partial tear to a full thickness tear.

This study was performed to determine whether any morphological change in the acromion is associated with rotator cuff tears. The hypothesis is that changes in the acromial structure are associated with rotator cuff tears.

\section{Aims and Objectives}

- To calculate Acromial Index in patients and to determine its significance in rotator cuff tears.

- Compare AI values in patients with rotator cuff tears and in patients with intact rotator cuff.

\section{Methodology}

A comparative study was performed on 42 patients between August 2020 and February 2021. Patients presenting to the orthopaedics OPD, Yenepoya Medical College, with rotator cuff tears, as well as

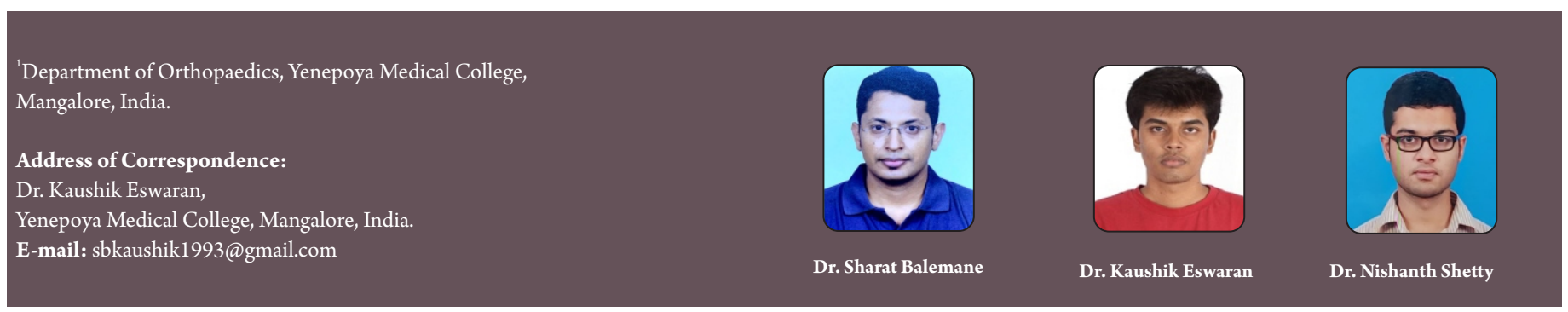

Submitted: 24 February 2021; Reviewed: 25 March 2021; Accepted: 28 April 2021; Published: 10 June 2021

Asian Journal of Arthroscopy | ISSN 2456-1169| Available on www.asianarthroscopy.com | DOI:10.13107/aja.2021.v06i01.018 |

This is an open access journal, and articles are distributed under the terms of the Creative Commons Attribution Non-Commercial-Share Alike 4.0 License (http://creativecommons.org/licenses/by-nc-sa/4.0) which allows others to remix, tweak, and build upon the work non-commercially as long as appropriate credit is given and the new creation are licensed under the identical terms. 


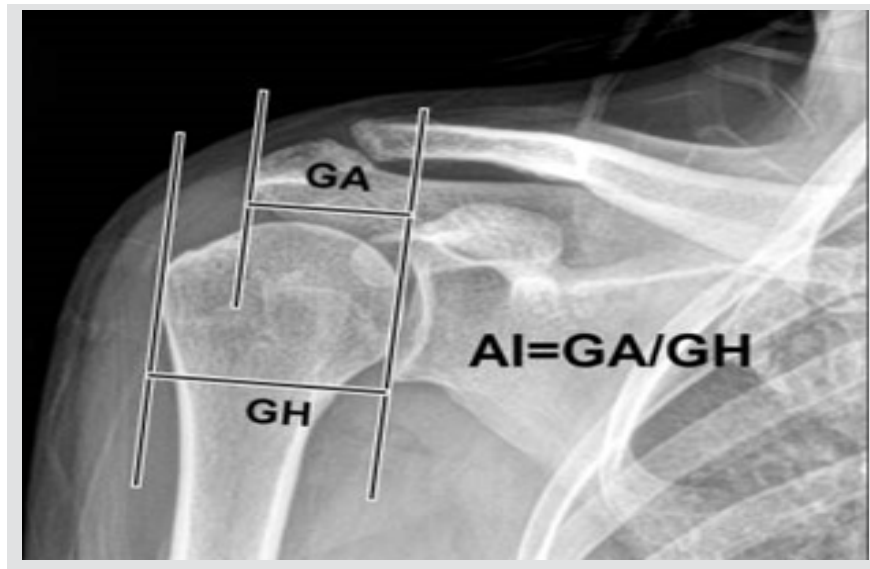

Figure 1: Calculating acromial index in AP radiograph.

other shoulder pathologies with intact rotator cuff such as frozen shoulder, were included in the study. Patients with fractures/dislocations of the shoulder, infections in the shoulder, arthritis of the shoulder and avascular necrosis of the humeral head were not included in the study. The patients were put into two groups, A and B. Group A included 21 patients with rotator cuff tears that were confirmed by clinical examination and ultrasound. Group B included 21 patients with intact rotator cuff, but had come to hospital with other diseases of shoulder such as impingement, frozen shoulder and calcific tendinitis. Radiographs of the affected shoulder were taken in AP view and axillary view. The Acromial Index (AI) was calculated in AP radiograph in patients of both groups, and were compared.

Standard AP radiograph of shoulder was taken with the arm in neutral or slight internally rotated position. Three parallel lines are drawn on the $\mathrm{AP}$ radiograph and the distances between those lines are measured. The first line connected the upper and lower tips of the glenoid rim. The second line was drawn on the lateral margin of the acromion parallel to the first line. The third line was drawn tangential to the most lateral part of the humerus head around the greater tuberosity. The AI was defined as the ratio of the distance from the glenoid to the lateral margin of the acromion (GA) divided by the distance from the glenoid rim to the lateral aspect of the humeral head $(\mathrm{GH})$. A higher AI indicates a larger lateral extension of the acromion. Statistical data was analysed using Windows SPSS version 23 software program. The discrete variables were presented as percentages/proportions. Continuous variables were expressed in terms of mean and standard deviation. Chi square test was used to compare the discrete variables between the groups. Student t-test was used to compare the continuous variables between the groups. ANOVA was used to test the statistical significance of multiple variables among different groups.

\section{Results}

This study included 42 patients out of which 23 patients were males and 19 were females. 21 patients had rotator cuff tears, of which 10 were males and 11 were females. The remaining 21 patients did not have rotator cuff tears, of which 13 were males and 9 were females. The non rotator cuff tear group consisted of 13 patients with frozen shoulder, 2 patients with shoulder impingement, and 6 patients with instability. The right shoulder was involved in 24 patients. The mean age of the patients in the rotator cuff group was 50.8 years, and in non rotator cuff tear group, it was 50.2 years. It was not statistically significant $(p=0.8384)$. The mean Acromial Index $(A I)$ in the rotator cuff tear group was 0.74 and in the non rotator cuff tear group it was 0.59 , which was statistically significant $(\mathrm{p}<0.001)$. The mean AI in males and females were 0.66 and 0.67 respectively, which was not statistically significant $(\mathrm{p}=0.746)$.

\section{Discussion}

This study compared the acromial indices of Indian patients and the results are similar to those reported by Dong Ho Kum et al. [8] and Nyffeler et al. [6]. The Acromial Index in rotator cuff group and non rotator cuff group was significantly different (mean 0.74, p<0.001). Hence, acromial index can be used as a predictive tool for rotator cuff tears. Several studies $[6,8,9,10,11]$ have also suggested that acromial index can be used as a predictive tool for rotator cuff tears. However, they have also reported that the relationship between the morphology of acromion and rotator cuff tears is still debatable. Moor et al. [12] and Balke et al. [13] described that distinct scapular morphologies including the AI accurately predicted the degenerative rotator cuff tear. However, Miyazaki et al. [7] reported contrasting results obtained from two different races: the AI was a possible cause of rotator cuff tears only in a Brazilian population and not in a Japanese population.

Acromial Index as a predictor for progression of rotator cuff tears was suggested by Kim et al [8]. There are several factors correlated with rotator cuff tears. Extrinsic factors are anatomic variables that compress the rotator cuff mechanically in impingement or under direct pressure from soft tissues. Examples include acromial spurs and morphological characteristics causing subacromial impingement or internal impingement. Intrinsic factors are related with degenerative changes within the tendon affected by vascularity or aging. However, the effects of these factors on the pathogenesis of rotator cuff tears remain unclear and the severity of symptoms is not proportionate to the size of a tear. Several recent studies show that extrinsic factors including the AI can be powerful predictors for progression of rotator cuff tears.

\section{Conclusion}

Acromial Index is a useful predictive tool for detecting rotator cuff tears in the Indian population. Further studies are required to assess its usefulness in predicting the progression of a rotator cuff tear. 


\section{References}

1. Neer CS., 2nd Impingement lesions. Clin Orthop Relat Res. 1983;(173):70-77.

2. Codman EA. The shoulder: rupture of the supraspinatus tendon and other lesions in or about the subacromial bursa. Boston, MA: Thomas Todd; 1934.

3. Bigliani LU, Morrison DS, April EW. The morphology of the acromion and its relationship to rotator cufftears. Orthop Trans. 1986;10:228.

4. Aoki M, Ishii S, Usui M. The slope of the acromion and rotator cuff impingement. Orthop Trans. 1986;10:228.

5. Banas MP, Miller RJ, Totterman S. Relationship between the lateral acromion angle and rotator cuff disease. J Should Elbow Surg. 1995;4(6):454-461. doi: 10.1016/S1058-2746(05)80038-2.

6. Nyffeler RW, Werner CM, Sukthankar A, Schmid MR, Gerber C. Association of a large lateral extension of the acromion with rotator cuff tears. J Bone JointSurg Am. 2006;88(4):800-805. doi: 10.2106/JBJS.D.03042.

7. Miyazaki AN, Itoi E, Sano H, et al. Comparison between the acromion index and rotator cuff tears in the Brazilian and Japanese populations. J Shoulder Elbow Surg. 2011;20(7):1082-1086.
8. Kim JR, Ryu KJ, Hong IT, Kim BK, Kim JH. Can a high acromion index predict rotator cufftears? Int Orthop. 2012;36(5):1019-1024.

9. Moor BK, Wieser K, Slankamenac K, Gerber C, Bouaicha S. Relationship of individual scapular anatomy and degenerative rotator cuff tears.J Shoulder Elbow Surg. 2014;23(4):536-541.

10. Torrens C, Lopez JM, Puente I, Caceres E. The influence of the acromial coverage index in rotator cuff tears. J Shoulder Elbow Surg. 2007;16(3):347-351.

11. Zumstein MA, Jost B, Hempel J, Hodler J, Gerber C. The clinical and structural long-term results of open repair of massive tears of the rotator cuff. JBone Joint Surg Am. 2008;90(11):2423-2431.

12. Moor BK, Wieser K, Slankamenac K, Gerber C, Bouaicha S. Relationship of individual scapular anatomy and degenerative rotator cuff tears.J Shoulder Elbow Surg. 2014;23(4):536-541.

13. Balke M, Liem D, Greshake O, Hoeher J, Bouillon B, Banerjee M. Differences in acromial morphology of shoulders in patients with degenerative and traumatic supraspinatus tendon tears. Knee Surg Sports Traumatol Arthrosc. 2016;24(7):2200-2205.

Declaration of patient consent: The authors certify that they have obtained all appropriate patient consent forms. In the form, the patient has given his consent for his images and other clinical information to be reported in the Journal. The patient understands that his name and initials will not be published, and due efforts will be made to conceal his identity, but anonymity cannot be guaranteed.

Conflict of interest: Nil Source of support: None

\section{How to Cite this Article}

Balemane S, Eswaran K, Shetty N | Acromial Index in Indian Population and its Significance on Rotator Cuff Tears | Asian Journal of Arthroscopy | January- June 2021; 6(1):08-10. 